\title{
Experimental evaluation of cohesive and adhesive bond strength and fracture energy of bitumen-aggregate systems
}

\author{
Jizhe Zhang ${ }^{\mathrm{a}, *}$, Gordon Airey ${ }^{\mathrm{a}}$, James Grenfell ${ }^{\mathrm{a}}$ \\ ${ }^{a}$ Nottingham Transportation Engineering Centre, University of Nottingham, Nottingham, \\ NG7 2RD, UK \\ *Email: evxjz3@nottingham.ac.uk
}

\section{Abstract}

Degradation of asphalt pavements is an inevitable phenomenon due to the combined effects of high traffic loads and harsh environmental conditions. Deterioration can be in the form of cohesive failure of the bitumen and/or bitumen-filler mastic or by adhesive failure between bitumen and aggregate. This paper presents an experimental investigation to characterise the cohesive and adhesive strength and fracture energy of bitumen-aggregate samples. The Pneumatic Adhesion Tensile Testing Instrument (PATTI) test and the Peel Test were used to quantify the tensile fracture strength and fracture energy of different bitumen-aggregate combinations, with a view to analyse the influence of several parameters on the strength of the bitumen film or bitumen-aggregate interface. From the experimental results, harder (40/60 pen) bitumen tends to show much higher tensile strength and fracture energy than softer (70/100 pen) bitumen. Tensile strength is shown to be sensitive to testing temperature with the failure regime changing from cohesive to mixed cohesive/adhesive failure with decreasing temperature. In addition, the results show that aggregate properties do not influence the bonding strength if cohesive failure occurs, but with adhesive failure, granite aggregate tends to produce a higher bonding strength than limestone aggregate in the dry condition. In terms of the Peel Test, the fracture energy experienced an increasing trend with increasing film thickness. However, the normalised toughness decreased when film thickness increased from $0.2 \mathrm{~mm}$ to $0.9 \mathrm{~mm}$.

Key words: Tensile fracture strength; Fracture energy; Peel test; Bitumen; Adhesion; Cohesion

\section{Introduction}


1

Asphalt mixtures, consisting of three phases; aggregates (coarse and fine), bitumen and air voids, are widely used as a pavement construction material. During their service life, asphalt pavements have to sustain heavy traffic loads and harsh environmental conditions leading to various degradation mechanisms such as load-induced fatigue cracking, temperature-induced thermal cracking and permanent deformation. Two factors that significantly influence the structural integrity of an asphalt mixture and essentially control is resistance to both mechanical and environmental damage is the adhesive bond between the bitumen and aggregates and the cohesive strength of the bitumen and/or bitumen-filler mastic [1-3]. It has been shown that the service performance and durability of an asphalt mixture depends on the strength of the bituminous film and is also controlled by the properties and strength of the bitumen-aggregate bond interface [4].

This paper aims to improve the understanding the combined mechanisms of cohesive and adhesive failure of the bitumen (cohesion) and bitumen-aggregate interface surface (adhesion) by determining the effect of temperature and bitumen film thickness on the bond strength properties of various bitumen-aggregate systems. Two bitumens with different penetration grades but the same chemical composition and two aggregates comprising a typical siliceous rock (granite) and carboniferous rock (limestone) were used in this study. The functional groups of bitumen were characterised with the help of Fourier Transform Infrared Spectroscopy (FTIR). Scanning Electron Microscopy (SEM) was used to analyse the surface morphology of aggregate, while the Mineral Liberation Analyser (MLA) focused on the mineral composition and mineral distribution of aggregate surface [5]. The Pneumatic Adhesion Tensile Testing Instrument (PATTI) was used to evaluate the tensile strength of different bitumen-aggregate combinations. This was thought to be an accurate method to not only determine the mechanical tensile strength of bitumen or bitumen-aggregate interface, but also identify the type of failure, either adhesive or cohesive, through the digital camera 
1 connected with the PATTI equipment [6]. An Environmental chamber was employed in this

2 research to condition the specimens in order to perform the PATTI test over a wide range of temperatures (from $-10^{\circ} \mathrm{C}$ to $40^{\circ} \mathrm{C}$ ). Furthermore, the fracture energy and normalised toughness of different bitumen-aggregate combinations were characterised at a steady loading speed using the Peel Test. In this research, Peel Tests were performed under different film thicknesses, with the purpose of analysing the influence of film thickness on fracture energy.

\section{Adhesive and Cohesive Testing}

The bonding between bitumen and aggregate has been attracting attention since the 1930s [79]. Over the last three decades, many theories and test methods have been developed for the purpose of studying the bitumen-aggregate interface. In order to understand the mechanisms of bitumen-aggregate adhesion, principles such as chemical bonding theory [10], electrostatic theory [11], mechanical theory [12] and thermodynamic theory [13] have been used by many researchers. According to these theories, aggregate which contains more $\mathrm{Ca}, \mathrm{Al}$ and $\mathrm{Mg}$ [14] and has a porous, slightly rough surface [15] is likely to give good adhesion with bitumen. While, bitumens which have more carboxylic acids and sulfoxides [16] and good wettability will bond well with aggregate. Testing methods such as the boiling water test and immersion test are used to characterise the adhesive properties of uncompacted mixes, but none of these tests can quantify adhesion [17]. The Indirect Tensile Test [18], Hamburg Wheel Tracking Device [19] and Saturation Ageing Tensile Stiffness (SATS) test [3, 20-22] are methods which focus on compacted mixtures to predict their degradation under simulated conditioning. The fracture mechanics of bitumen have been studied with the utilisation of 3-Point Bending [23], Plug Pull-Out [24] and Double Cantilever Beam [25]. Furthermore, the bonding strength between two different pavement layers has been measured with the help of pull-off and shear tests [26]. These methods mentioned before have been used for several years and considered 
1 to be realistic, but cannot accurately characterise the mechanical properties of thin bitumen

2 films and bitumen-aggregate interfaces under the effect of temperature and film thickness.

3 Previous research has shown that there are several factors which may influence cohesion of a

4 bitumen film and adhesion of a bitumen-aggregate interface, including the nature and the

5 thickness of bituminous binder, the type of aggregate and temperature. Kinloch [27] found that

6 the bonding strength of polymeric adhesives measured using the Peel Test was inversely

7 proportional to the film thickness. The Peel Test has also been shown to be a suitable method

8 to measure the fracture energy of bitumen-aggregate interfaces with this parameter providing

9 a characteristic value for the failure of the joint [28]. Bitumen with a low penetration grade tends to give a strong bond with aggregate while temperature plays an important role in terms of bonding strength and failure type. Genin and Cebon [24] observed that a combination of brittle fracture in the bitumen and fracture along the interface between bitumen and substrate was the mechanism of failure at low temperatures. However at high temperatures, the failure mechanism changed to void coalescence and void growth. For aggregates, granite tends to form a strong bond with bitumen in comparison with limestone because of their mineral composition [29].

17

\section{Materials}

\subsection{Bitumen}

Two base bitumens with penetration grades of $40 / 60$ pen and $70 / 100$ pen were used in this research study. For the $40 / 60$ pen bitumen, the penetration is $46(\mathrm{dmm})$ at $25^{\circ} \mathrm{C}$ with a softening point of $51.2^{\circ} \mathrm{C}$. While for the $70 / 100$ pen bitumen, the penetration is $81(\mathrm{dmm})$ at $25^{\circ} \mathrm{C}$ and the softening point is $45.2^{\circ} \mathrm{C}$.

The functional groups of the bitumen were characterised by means of Fourier Transform Infrared Spectroscopy (FTIR) using an Agilent 670 FTIR spectrometer and the procedure suggested by Marsac et al [30]. The process involved firstly placing a small amount of bitumen 
1 (10mg) onto the scanning window of the apparatus. During testing, the beam used in the FTIR

2 test is generated by starting with a broadband light source which contains the full spectrum of wavelengths to be measured. This beam containing multiple frequencies of light was shone at the specimen with the detector used to measure how much of that beam was absorbed by the sample. This process is repeated a number of times and the data analysed to determine the

6 absorption at each wavelength.

7 Figure 1 illustrates the infrared spectroscopy curves of the 40/60 pen and 70/100 pen bitumen at $25^{\circ} \mathrm{C}$. According to previous research [31], the absorption peaks at $2921 \mathrm{~cm}^{-1}$ and $2852 \mathrm{~cm}^{-1}$ correspond to $\mathrm{C}-\mathrm{H}$ asymmetrical stretching. The absorption peak of $\mathrm{S}=\mathrm{O}$ is at $1030 \mathrm{~cm}^{-1}$, which is used to detect the existence of sulfoxides. In terms of carboxylic acids, their $\mathrm{C}=\mathrm{O}$ and $\mathrm{C}-\mathrm{O}$ stretch absorption peaks are at $1730-1700 \mathrm{~cm}^{-1}$ and $1320-1210 \mathrm{~cm}^{-1}$, respectively. It can be seen that the absorbance of the 40/60 pen and 70/100 pen bitumen are nearly identical. The functional groups which can contribute to the bitumen-aggregate bonding, such as sulfoxides and carboxylic acids, can be detected from FTIR curves, but their components are very small. granite) have considerable differences in terms of their mineral composition and surface morphology and therefore the bonding strength of the bitumen-aggregate interface associated with them. SEM was used to analyse the surface morphology of aggregates to observe and analyse the apparent shape, porosity size and even surface texture of the aggregate. Before testing, samples were prepared by pressing an adhesive patch which was attached to an aluminium stub onto filter paper covered with aggregate particles. A minimum of two samples from each filter paper were prepared and then coated with platinum to minimise surface charging. To observe these specimens, a Philips XL30 SEM equipped with a field emission 
1 gun was operated at an accelerating voltage of $20 \mathrm{kV}$. The images were taken in both the

2 secondary electron (SE) and back-scattered electron (BSE) imaging mode.

3 Figures 2 and 3 show SEM micrographs of limestone and granite using both SE and BSE. From

4 Figure 2 (a) it is clear that the surface texture of limestone is loosely organised with coarse

5 fractions and has a rough surface. The rough surface will result in more area being available to

6 interact with the bitumen. The crystal particles have different sizes but most of them are less

7 than $10 \mu \mathrm{m}$ in dimension. It can be seen from Figure 2 (b) that the limestone surface has many

8 pores with sizes from 2-10 $\mu \mathrm{m}$. However, differences in terms of mineral phase cannot be

9 detected; this reveals that the mineral composition of limestone is very uniform. In contrast,

10 the granite has a delicate texture and dense structure, as shown in Figure 3 (a). The crystalline grains are partly oriented vertically to the granite surface and form a smoother surface. According to Figure 3 (b), it is hard to detect any pores on the granite surface but it does consist of many different types of mineral phases. This reveals that the size of pores is very small and the mineral composition is very complex.

A MLA was used to analyse the mineral properties, mineral texture and grain size of aggregates. Samples were first prepared by casting aggregates in resin followed by polishing of the surface. Then, carbon coating was applied to get an electron conductive surface. An FEI Quanta 600 SEM with MLA capability was used for the mineral analysis. This setup combined an automated SEM and multiple Energy Dispersive X-ray detectors with automated quantitative mineralogy software. During testing, the SEM collects BSE images and energy dispersive X-ray data for a series of frames step by step across the specimen surface. Measurement of the backscattered electron intensities allows for the segmentation of mineral phases within each particle section, while EDX analysis of a given phase allows for phase identification. 
1 As shown in Figure 4, minerals in the granite sample exhibit considerable texture and the

2 distribution is more complex, while the limestone surface is simple and calcite makes up almost

3 all of the area. Small quartz grains are also well-distributed in the calcite minerals in the

$4 \quad$ limestone sample. These results correlated well with the SEM results.

5 Summaries of the limestone and granite mineral composition, as determined by MLA, are

6 provided in Tables 1 and 2, respectively. For the limestone sample, calcite $\left(\mathrm{CaCO}_{3}\right)$ is the

7 predominant phase when compared to the other minerals present, with $99.33 \%$ by weight.

8 Other minerals, including quartz and iron-oxide, are only present at less than $1 \%$. Albite

$9\left(\mathrm{NaAlSi}_{3} \mathrm{O}_{8}\right)$ is the dominant mineral in granite with a presence of $73.17 \%$ by weight, followed by chlorite and anorthite, which account for $15.58 \%$ and $10.75 \%$ respectively. In addition, there are small amounts of apatite and iron-oxide, both of which only account for $0.5 \%$. The chemical compositions of these two aggregates are shown in Table 3. The predominant elemental species in the limestone and granite are $\mathrm{Ca}$ and $\mathrm{Si}$, respectively. This difference in chemical composition may affect the mechanical properties of the bitumen-aggregate interface.

\section{Experimental Procedures}

\subsection{Pneumatic Adhesion Tensile Testing Instrument (PATTI) Test}

The PATTI equipment was used to evaluate the fracture strength of a bitumen-aggregate sample geometry either in terms of the cohesive bond strength of the bitumen or the adhesive bond strength of the bitumen-aggregate interface. This equipment was developed by the National Institute of Standards and Technology (NIST) with the equipment used for the PATTI test shown in Figure 5. The PATTI device is used to measure tensile strength, while the camera is used for the analysis of the failure surface. Figure 6 shows a cross-sectional schematic of the setup of the PATTI with the piston attached to a pull-stub which in turn is attached by means of the bitumen coating to the aggregate substrate. 
1 In order to get a well bonded specimen, the aggregate surface and the pull-stub should be wiped carefully using a damp paper towel to remove any dust. After that, the aggregate and pull-stub are placed in an oven and heated to a temperature of $70^{\circ} \mathrm{C}$ for one hour. The bitumen must be heated to $150^{\circ} \mathrm{C}$ for 1 hour to allow it to be fluid enough to coat the aggregate plate. The liquid bitumen is then poured onto a prepared aggregate plate (with the dimensions of $100 \mathrm{~mm} \mathrm{x}$

$6100 \mathrm{~mm} \times 20 \mathrm{~mm}$ ) which is pressed immediately by a metal pull-stub to establish a good 7 bitumen-aggregate bond. In this process the film thickness of bitumen was controlled by the 8 pull-stub itself to make sure all specimens have a $0.8 \mathrm{~mm}$ bitumen film, as shown in Figure 7.

9 Finally, the excess bitumen at the edge of pull-stub should be removed by using a heated pallet 10 knife.

11 During the test, air pressure generated by the PATTI is transmitted to the piston which is placed over the pull stub and screwed onto the reaction plate. The air pressure induces an airtight seal formed between the piston gasket and the aggregate surface. A constant rate of pulling pressure, which is set in the pressure control panel, is applied to the sample. The test generates data in the form of tensile pressure versus testing time which is recorded by the data acquisition system. The maximum tensile pressure to separate the bitumen from substrate is captured by the software. This pressure is converted to its pull-off tensile strength, as expressed in the following equation:

$19 \quad P O T S=\frac{\left(B P \times A_{g}\right)-C}{A_{p s}}$ where, POTS is the pull-off tensile strength $(\mathrm{kPa}), B P$ is air pressure $(\mathrm{kPa}), A_{g}$ is the contact area of gasket with relation plate $\left(\mathrm{mm}^{2}\right), C$ is the piston constant and $A_{p s}$ is the area of pullstub $\left(\mathrm{mm}^{2}\right)$.

\subsection{Peel Test}


1 The Peel Test is a method for measuring the fracture energy of flexible laminates. A flexible

2 arm and a rigid substrate are bonded using the adhesive. The force is applied to the flexible arm so as to pull it apart from the rigid substrate at a constant rate. During this process, fracture occurs along the length of the bond. In this research, the aggregate is the rigid substrate, which is bonded to the aluminium peel arm using bitumen as the adhesive layer with a range of thicknesses from $0.2 \mathrm{~mm}$ to $0.9 \mathrm{~mm}$.

The sample preparation consists of the following steps [32]:

1. Surface pre-treatment. Aggregate surface and peel arm are wiped gently using a damp paper towel to remove any dust.

2. Pre-heating the aggregate and the bitumen. The aggregate and peel arm are then placed in an oven at $150^{\circ} \mathrm{C}$ for 1 hour. Bitumen is preheated to $150^{\circ} \mathrm{C}$ prior to making the joint.

3. Placing the sharp crack initiator. A release film (PTFE) of dimensions $12 \mathrm{~mm} \times 12 \mathrm{~mm}$ $\times 75 \mu \mathrm{m}$ is placed on the aggregate surface at one end.

4. Five wire spacers with a length of $20 \mathrm{~mm}$ are placed on the aggregate. The diameter of the wire controls the thickness of the bitumen (adhesive) layer.

5. The liquid bitumen is applied (at $150^{\circ} \mathrm{C}$ ) evenly along the surface of the aggregate.

6. The preheated aluminium peel arm (of length $50 \mathrm{~mm}$ longer than the aggregate and of thickness $0.2 \mathrm{~mm}$ ) is placed on the top of the bitumen layer.

7. Gentle pressure is applied on top of the joint to control the thickness of the bitumen layer. The pressure should be uniformly distributed over the bond area. The bonded specimen is then cooled at ambient temperature overnight. The excess adhesive at the edges of the specimen should be trimmed with a heated knife.

An Instron 5969 machine which can supply a constant rate of grip separation was used to measure the tensile force during the peel test. The sample was attached to a linear bearing to get a highly accurate and smooth motion during testing. The linear bearing is then attached to 
$5 \quad R=\dot{C} /(1-\cos \theta)$

the Instron machine. During the test, the free end of the peel arm was bent to an applied peel angle of $90^{\circ}$ and this angle is maintained by the linear bearing system, as shown in Figure 8 . According to equation 2, the displacement velocity of the cross-head of the Instron machine was equivalent to the fracture displacement velocity when the peel angle is $90^{\circ}$ :

where, $R$ is the peel rate, $\dot{C}$ is the crosshead displacement rate and $\theta$ is the peel angle.

A peel speed of $10 \mathrm{~mm} / \mathrm{min}$ was used in this test. The tensile force was recorded during the fracture development so as to calculate the fracture energy in the next step. The fracture energy, $G_{a}$, is considered to be a geometry-independent parameter which reflects (a) the energy to break the interfacial bonding forces and (b) the energy dissipated locally ahead of the peel front in the plastic or viscoelastic zone. The input energy to the Peel Test needs to be resolved into the various deformation energies; elastic, plastic and adhesive fracture energy [33]. The adhesive fracture energy $G_{a}$ can be derived as follows:

$G_{a}=\frac{1}{b}\left(\frac{d U_{e x t}}{d a}-\frac{d U_{S}}{d a}-\frac{d U_{d t}}{d a}-\frac{d U_{d b}}{d a}\right)$

where, $d U_{\text {ext }}$ is the external work, $d U_{s}$ is the stored strain energy in the peeling arm, $d U_{d t}$ is the energy dissipated during tensile deformation of the peeling arm and $d U_{d b}$ is the energy dissipated during bending of the peeling arm near the peel front.

In order to calculate the plastic deformation energy associated with the peel arm, it is first necessary to have knowledge of the tensile stress-strain characteristics of the peel arm material. So, the aluminium peel arm was subjected to tensile testing at the same cross-head speed.

\section{Results and discussion}

\subsection{PATTI cohesive and adhesive bond strength measurements}

In order to characterise the influence of temperature on the bond strength, the PATTI test was performed at six temperatures from $-10^{\circ} \mathrm{C}$ to $40^{\circ} \mathrm{C}$ at $10^{\circ} \mathrm{C}$ intervals. Samples were conditioned 
1 in an environmental chamber for 3 hours to get a homogeneous temperature distribution.

2 During the test, a constant rate of air pressure was applied to get repeatable results.

3

4

5

\subsubsection{Influence of temperature and bitumen type}

Figure 9 shows examples of the applied pressure (tensile strength) versus time at different temperatures for samples prepared with the $40 / 60$ pen bitumen and a granite substrate. It can be seen that the increase of applied pressure versus time at different temperatures is almost identical, confirming the successful application of a constant rate of pulling pressure for these tests. The specimen response is characterised by the linear increase in pressure (tensile stress) until the pressure exceeds the cohesive strength of the bitumen or the adhesive strength of the bitumen-aggregate system and suddenly decreases to zero. Failure can be taken to occur at the peak pressure (tensile stress) and is defined as the pull-off tensile strength.

Four tests (similar to those shown in Figure 9) were performed for each bitumen-aggregate combination at each temperature and the average tensile strength versus temperature curves, as well as the error bars which represent the standard deviation of original data, are shown in Figure 10. From this figure it can be seen that in the temperature range from $-10^{\circ} \mathrm{C}$ to $10^{\circ} \mathrm{C}$, the tensile strength of all four combinations of bitumen and aggregates shows an increasing trend from between 1500 and $2500 \mathrm{kPa}$ to between 2500 and $3500 \mathrm{kPa}$. However, as the temperature exceeds $10^{\circ} \mathrm{C}$, all the specimens experienced a steady decline in terms of tensile strength with values dropping to only about $500 \mathrm{kPa}$ at $40^{\circ} \mathrm{C}$. It should be pointed out that the lowest temperature does not correspond to the highest tensile strength. This phenomenon is in agreement with the relationship found for tensile strength versus bitumen stiffness modulus as shown in Figure 11 [34]. These results show an equivalent behavior where very high stiffness modulus (low temperatures) results in lower tensile strength [35].

As expected based on previous studies [28], samples prepared with 40/60 pen bitumen have a higher tensile strength than those prepared with $70 / 100$ pen bitumen from $0{ }^{\circ} \mathrm{C}$ to $40^{\circ} \mathrm{C}$. It can 
1 therefore be concluded that bitumen with low penetration and high softening point can develop

2 a stronger bond with aggregate under dry conditions.

3

4

5

\subsubsection{Influence of Aggregate Type}

In the temperature range from $-10^{\circ} \mathrm{C}$ to $10^{\circ} \mathrm{C}$, as shown in Figure 10 , tensile strengths for $40 / 60$ pen bitumen and granite combination are over $10 \%$ higher when compared with those prepared with limestone aggregate. For $70 / 100$ pen bitumen, this phenomenon only occurred at $-10^{\circ} \mathrm{C}$ and $0^{\circ} \mathrm{C}$ due to the lower brittle to ductile transition temperature associated with the softer bitumen. A digital image of the failure surfaces at the end of the PATTI test were captured using the equipment's integrated camera for all the bitumen-aggregate combinations at all six test temperatures. Images of the failure pattern for the 40/60 pen bitumen with granite aggregate substrate are shown in Figure 12. From Figure $12(a-c)$ it can be seen that failure surfaces from $-10^{\circ} \mathrm{C}$ to $10^{\circ} \mathrm{C}$ exhibit cohesive-adhesive mix mode failure with some adhesive failure occurring at the edge of failure surfaces. This implies that the cohesive strength of bitumen is stronger than the adhesive strength of the bitumen-aggregate interface. It also means that the tensile fracture strength when adhesive failure occurs is influenced by the mineral properties of aggregate. As granite contains more $\mathrm{Si}$ and $\mathrm{Al}$, which can form strong chemical bonds with carboxylic acids and sulfoxides in bitumen under dry conditions, the tensile strengths for the two granite-bitumen combinations were greater than the two limestone-bitumen combinations. This meant that at $-10^{\circ} \mathrm{C}$, the two types of bitumen (40/60 pen and the softer $70 / 100$ pen) tended to have the same tensile strength with the same aggregate.

With temperature increase, the two aggregates seem to give the same tensile strength. This is due to the failure mechanism changing from adhesive to cohesive failure as shown in Figure 12(d-f). The adhesive strength at the bitumen-aggregate interface exceeds the bitumen cohesive strength at temperatures of $20^{\circ} \mathrm{C}$ and higher. In this region, the mineral properties of the aggregate cannot influence the tensile fracture strength results. 
1

2

3

4

5

6

7

\subsubsection{Failure surface analysis}

From $-10^{\circ} \mathrm{C}$ to $10^{\circ} \mathrm{C}$, as shown in Figure 12 for the $40 / 60$ pen bitumen with granite aggregate substrate, the failure surfaces are flat and shiny and their texture is smooth. In addition, there is no evidence of voiding being observed in these specimens. Within this temperature region, the 40/60 pen bitumen can be considered to behave in a brittle manner. As bitumen, aggregate and the steel stub have different Poisson's ratios and Young's Moduli, when load is applied to the specimen, it is impossible to get the same tensile stress everywhere, as the stress distribution is non-uniform. Also, during sample preparation, it is hard to get ideal adhesion without any physical defect around the edge, especially at the bitumen-aggregate interface. The faults existing around the film edge play an important role as stress concentrators. During the test, the stress which is applied to the specimen is focused on these faults to cause the fracture to start at these points. At the same time with temperature decrease, the bitumen becomes harder and more likely to experience a brittle-type failure mode. This brittle failure, together with the shift from cohesive to adhesive failure, results in a decrease in the tensile fracture strength as the temperature decreases from $10^{\circ} \mathrm{C}$ to $-10^{\circ} \mathrm{C}$.

When the temperature is over $20^{\circ} \mathrm{C}$, several round voids exist on the failure surfaces. With increasing temperature, the size of the voids increase but the quantity (number) of voids decreases. This is because the bitumen transforms from brittle behavior to ductile behavior as the temperature increases. The void formation can be explained by the flow and voiding failure mechanisms for ductile failure of bitumen films [25]. At low aspect ratios $A=D / h$ (film diameter D and thickness $\mathrm{h}$ ), no voiding is observed and the material flows over the central area of the specimen. If the specimen has high aspect ratio but very low strain rate, voids are formed during the fracture process but they do not leave visible evidence on the final surface. When samples have aspect ratios in the range of $8-100$, voids nucleate and coalesce. In this test, the aspect ratio of the sample is over 25 , so all failures behave with this voiding mechanism 
1 at high temperatures. For samples at $20^{\circ} \mathrm{C}$, voids are visible but do not fully coalesce on the

2 failure surface because the binder viscosity is still relatively high at this temperature. With

3 temperature increase, binder viscosity decreases gradually so that it can flow more easily and

4 small voids combine into bigger voids.

5

6

7

8

9

10

11

\subsection{Peel Test}

\subsubsection{Parameter calculations}

The tensile stress-strain test of the peel arm was performed at a speed of $10 \mathrm{~mm} / \mathrm{min}$ until fracture occurred. The tensile stress-strain curve is shown in Figure 13. In order to describe the elastic and plastic deformation of the peel arm, the stress-strain curve should be fitted according to a bi-linear or power law form [28]. The purpose of the bi-linear and power law curve fits is to get a number of parameters which are used to calculate the fracture energy.

When $\varepsilon<\varepsilon_{y}$,

$\sigma=E_{1} \varepsilon$

When $\varepsilon>\varepsilon_{y}$, according to the power law work hardening model:

$\sigma=\sigma_{y}\left(\frac{\varepsilon}{\varepsilon_{y}}\right)^{n}$

According to the bi-linear model:

$\sigma=\sigma_{y}+\alpha E_{1}\left(\varepsilon-\varepsilon_{y}\right)$

where $\sigma_{y}$ is yield stress and $\varepsilon_{y}$ is the yield strain, $E_{1}$ is the elastic modulus of the peel arm, $n$ is the work hardening coefficient of the peel arm, $\alpha$ is the ratio of plastic modulus to elastic modulus, $E_{2} / E_{1}$.

The measured stress-strain curve was modelled using the bi-linear model and power law model as shown in Figures 14 and 15, respectively. From these two figures it can be seen that both models provide an acceptable fit with the measured data. Table 4 shows the parameters gained from the fitting process. 
1 The same bitumen and aggregate combinations as used in the PATTI test were used in the Peel

2 Test. Five steel washer with thicknesses from $0.2 \mathrm{~mm}$ to $0.9 \mathrm{~mm}$ were used to control the

3 thickness of the bitumen film. All peel tests were conducted at $20^{\circ} \mathrm{C}$ with a speed of $10 \mathrm{~mm} / \mathrm{min}$,

4 which is the same condition as for the peel arm stress-strain test. The tensile force was recorded

5 by the Instron machine during testing and the tensile strength versus displacement curve was

6 plotted, as shown in Figure 16. It was observed that the tensile force remained at an

7 approximately constant value after the initial stage. This means that the fracture experienced a steady propagation. Normally, at least $50 \mathrm{~mm}$ of constant crack propagation region will be defined with the average value of the tensile force being calculated as shown in Figure 16. This average tensile force was used to calculate the values of the bitumen-aggregate fracture energy. Four tests were performed on each bitumen-aggregate combination. The average force of each sample and the parameters in Table 4 were entered into the Microsoft Excel macro IC Peel software to calculate fracture energy [36]. Fracture energy results in terms of both the bi-linear model and power law model were calculated. For all tests, the fracture energy calculated according to the bi-linear model is slightly higher than that from the power law model, but the difference is less than $5 \%$. Therefore it is possible to select either model to analyse the different bitumen-aggregate combinations. In this research, the bi-linear model was employed for the analysis.

\subsubsection{Influence of bitumen and aggregate}

Figure 17 shows the average fracture energy of specimens with a film thickness of $0.25 \mathrm{~mm}$ according to the bi-linear model, while the error bars are the standard deviation of the original results. It is clear that specimens prepared with 70/100 pen bitumen have lower fracture energy than those with $40 / 60$ pen bitumen. This is because 40/60 pen bitumen is stiffer than 70/100 pen bitumen, so higher stresses are needed to break (fracture) the binder cohesively. This was in good agreement with the PATTI test results. When considering the same bitumen, samples 
1 prepared with the two aggregates tended to yield almost the same result. This was because the

2 samples exhibited cohesive failure at $20^{\circ} \mathrm{C}$. As explained in section 5.1.2, the aggregate

3 properties cannot influence the bonding strength of the peel test sample when cohesive failure

4 occurs.

5

6

7

8

9

\subsubsection{Influence of film thickness}

With the purpose of characterising the influence of film thickness on fracture energy, the Peel Test was carried out with two bitumen types and limestone substrates with thicknesses from $0.2 \mathrm{~mm}$ to $0.9 \mathrm{~mm}$ in five steps: $0.2 \mathrm{~mm}, 0.25 \mathrm{~mm}, 0.38 \mathrm{~mm}, 0.5 \mathrm{~mm}$, and $0.9 \mathrm{~mm}$. Figure 18 illustrates the change in fracture energy due to the increase of film thickness. In terms of failure mode, all failure surfaces exhibited cohesive rupture, as shown in Figure 19. As the bitumen film thickness was increased, the fracture energy of these two types of bitumen experienced a steady increase as more energy was dissipated in the bulk of the bitumen binder. This could be attributed to the increased viscous flow of the base bitumen as the bitumen film became thicker. Furthermore, large differences in the magnitude of fracture energy were shown between these two types of bitumen. The fracture energy for $40 / 60$ pen bitumen exceeded that of the $70 / 100$ pen bitumen for every film thickness. This was in good agreement with the measured tensile strength of the bitumen using the PATTI test.

If the fracture energy is divided by its film thickness, it gives the normalised toughness of each specimen. According to previous researchers, the normalised toughness is a better characterisation parameter than the energy per unit area for ductile thin films, since there is no clearly defined area of fracture surface created in the ductile failure process [25]. Figure 20 presents the relationship between normalised toughness and film thickness. It was illustrated that the normalised toughness of these two types of bitumen decreased when the film thickness increased from $0.2 \mathrm{~mm}$ to $0.9 \mathrm{~mm}$. In this film thickness region, the normalised toughness decreases with bitumen film thickness in a power law relationship. Fitting of the experimental 
1 data with a power law function produced coefficients of determination $\left(\mathrm{R}^{2}\right)$ of 0.9877 and

20.9979 for the 40/60 pen bitumen and 70/100 pen bitumen, respectively. It can be seen that less

3 energy was needed to fracture bitumen of unit area when the film thickness increases from

$4 \quad 0.2 \mathrm{~mm}$ to $0.9 \mathrm{~mm}$.

5

6

7

8

9

\section{Conclusions}

This paper reports findings from an investigation of the bonding strength and fracture energy of different bitumen-aggregate combinations. Several factors, such as bitumen hardness (penetration), surface properties of aggregate, testing temperature and film thickness were considered in this research to analyse their influence on the tensile fracture strength of the bitumen film or the bond strength of the bitumen-aggregate interface. The following major findings can be taken from this study:

- According to FTIR results, the two types of bitumen have almost the same functional groups and differ only in terms of the penetration grade (hardness). SEM and MLA are reliable methods to characterise the surface properties of aggregate. The limestone aggregate tended to have more surface area to bond with bitumen, while the granite aggregate contained more mineral phases known to provide good adhesion with bitumen.

- The tensile strength of the bitumen film and the bitumen-aggregate interface measured with the PATTI test was shown to be sensitive to temperature. The failure pattern was shown to change from cohesive failure to mixed cohesive/adhesive failure as the test temperature decreased from $40^{\circ} \mathrm{C}$ to $-10^{\circ} \mathrm{C}$. At the same time, the bitumen failure behavior changes from brittle to ductile behavior as the temperature increase from $-10^{\circ} \mathrm{C}$ to $40^{\circ} \mathrm{C}$. These combined effects resulted in the maximum tensile fracture strength for the various bitumen-aggregate combinations occurring at approximately $10^{\circ} \mathrm{C}$.

- It was found that aggregate surface properties play an important role in the tensile strength when adhesive failure occurred at low temperatures. The influence of aggregate type 
indicates that mineral composition seems more important than morphology in terms of

2 bonding with bitumen.

- The Peel Test is a suitable method to characterise the fracture energy of bitumen films. The surface properties of aggregate cannot influence the fracture energies of specimens with $0.2 \mathrm{~mm}$ film thickness or greater due to the cohesive failure regime experience with the test at a temperature of $20^{\circ} \mathrm{C}$ and a displacement rate of $10 \mathrm{~mm} / \mathrm{min}$ under dry conditions. However, bitumen type dominates the magnitude of the fracture energy.

- As film thickness increases, the fracture energy of the two types of bitumen experienced a steady increase. However, the normalized toughness decreased with increasing film thickness. Since the fracture energy and normalised toughness show film thickness dependency, it is of great importance to prepare specimens in which the bitumen film mirrors mixture film thickness as closely as possible.

\section{References}

1. L.D. Poulikakos, M.K. Tiwari, M.N. Partl. Analysis of failure mechanism of bitumen films. Fuel 2013; 106: 437-447.

2. D. Cebon. Interaction between Heavy Vehicles and Roads, SAE International, 1993.

3. G.D. Airey, A.C. Collop, S.E. Zoorob, R.C. Elliott. The influence of aggregate, filler and bitumen on asphalt mixture moisture damage. Construction and Building Materials 2008; 22(9): 2015-2024.

4. L.T. Mo, M. Huurman, M.F. Woldekidan, S.P.Wu, A.A.A. Molenaar. Investigation into material development and optimization of improved ravelling resistant porous asphalt concrecte. Materials \& Design 2010; 31(7):3194-3206.

5. J. Grenfell, N. Ahmad, Y. Liu et al. Assessing asphalt mixture moisture susceptibility through intrinsic adhesion, bitumen stripping and mechanical damage. Road Materials and Pavement Design 2014; 15(1): 131-152.

6. Y-R Kim, I Pinto and S-W Park. Experimental evaluation of anti-stripping additives in bituminous mixtures through multiple scale laboratory test results. Construction and Building Materials 2012; 29: 386-393.

7. V. Nicholson. Adhesion tension in asphalt pavements, Its significance and methods applicable in its determination. Proceedings of the association of paving technologists 1932; 28-48.

8. V.B.Saville and E.O.Axon. Adhesion of asphalt binders to mineral aggregates. Proceeding of the association of asphalt paving technologists 1937; 86-101. 
9. A.W. Hefer, D.N. Little, R.L. Lytton. A Synthesis of Theories and Mechanisms of Bitumen-Aggregate Adhesion Including Recent Advances in Quantifying the Effect of Water (With Discussion). Journal of the association of asphalt paving technologists 2005; 74:139-196.

10. R.E. Robertson, Chemical Properties of Asphalts and Their Effects on Pavement Performance, Transportation Research Circular No. 499. Washington, D.C., 2000.

11. J. Schultz and M. Nardin, Theories and Mechanisms of Adhesion, Adhesion Promotion Techniques-Technological Application, New York: Marcell Dekker, Inc. 1994. pp: 126.

12. R.L. Terrel and S. Al-Swailmi, Water Sensitivity of Asphalt-Aggregate Mixes: Test Selection. No. SHRP-A-403. 1994.

13. N. Ahmad. Asphalt Mixture Moisture Sensitivity Evaluation using Surface Energy Parameters. Ph.D dissertation at University of Nottingham, UK 2011.

14. U. Bagampadde, U. Isacsson and B.M. Kiggundu, Classical and Contemporary Aspects of Stripping in Bituminous Mixes, Road Materials and Pavement Design 2004; 5(1): 743.

15. A.R. Tarrar and V. Wagh, The Effect of the Physical and Chemical Characteristics of the Aggregate on Bonding, Strategic Highway Research Program Report SHRPA/UIR-91-507, Washington, D.C.: National Research Council (1992).

16. J.C. Petersen, H. Plancher, Model Studies and Interpretive Review and the Competitive Adsorption and Water Displacement of Petroleum Asphalt Chemical Functionalities on Mineral Aggregate Surfaces, Petroleum Science \& Technology 1998; 16(1-2): 89-131.

17. Y. Liu, A. Apeagyei, N. Ahmad et al. Examination of moisture sensitivity of aggregatebitumen bonding strength using loose asphalt mixture and physic-chemical surface energy property tests. International Journal of Pavement Engineering 2014; 15(7): 657670.

18. R.P. Lottman, Predicting Moisture-Induced Damage to Asphaltic Concrete Field Evaluation, NCHRP 246, 1982.

19. T. Aschenbrener, Evaluation of Hamburg wheel-tracking device to predict moisture damage in hot-mix asphalt. Transport Res Record 1995; 1492: 193-201. TRB, National Research Council, Washington DC.

20. A.C. Collop, Y.K. Choi, G.D. Airey, et al. Development of the saturation aging tensile stiffness (SATS) test. Proceeding of the ICE-Transport 2004; 157(3): 163-171.

21. G.D. Airey, Y.K. Choi, A.C. Collop, et al. Combined Laboratory Aging/Moisture Sensitivity Assessment of High Modulus Base Asphalt Mixtures (With Disscussion). Journal of the Association of Asphalt Paving Technologists 2005; 74.

22. J. Grenfell, N. Ahmad, G. Airey et al. Optimising the moisture durability SATS conditioning parameters for universal asphalt mixture application. International Journal of Pavement Engineering 2012; 13(5): 433-450.

23. O. Portillo, D. Cebon. Experimental and numerical investigation of fracture mechanics of bitumen beam. Engineering Fracture Mechanics 2013; 97: 281-296.

24. G.M. Genin, D. Cebon. Fracture Mechanics in Asphalt Concrete. Road Materials and Pavement Design 2000; 1(4): 419-450.

25. J.A.F. Harvey, D. Cebon. Failure Mechanism in Viscoelastic Films. Journal Materials Science 2003; 38: 1021-1032.

26. Y. Xiao, M.F.C. van de Ven, A.A.A. Molenaar, Z. Su, K. Chang. Design approach for epoxy modified bitumen to be used in antiskid surfaces on asphalt pavement. Construction and Building Materials 2013; 41: 516-525.

27. A.J. Kinloch, Review: The Science of Adhesion Part 2 Mechanics and Mechanisms of Failure, Journal of Materials Science 1982; 17: 617-651. 
28. B.R.K. Blackman, S. Cui, A.J. Kinloch, A.C. Taylor. The development of a novel test method to assess the durability of asphalt road-pavement materials. International Journal of Adhesion and Adhesives 2013; 42: 1-10.

29. M. Horgnies, E. Darque-Ceretti, H. Fezai, E. Felder. Influence of the interfacial composition on the adhesion between aggregates and bitumen: Investigations by EDX, XPS and peel tests. International Journal of Adhesion and Adhesive 2011; 31(4): 238247.

30. P. Marsac, N. Piérard, L. Porot, et al. Potential and limits of FTIR methods for reclaimed asphalt characterisation. Materials and Structures 2014; 1-14.

31. S.P. Wu, L. Pang et al. Influence of aging on the evolution of structure, morphology and rheology of base and SBS modified bitumen. Construction and Building Materials 2009, 23: 1005-1010.

32. N. Ahmad, S. Cui, B.R.K. Blackman, A.C. Taylor, A.J. Kinloch and G.D. Airey. Predicting Moisture Damage Performance of Asphalt Mixtures. Nottingham Transportation Engineering Centre Report 2011, Report Number: 11091.

33. A.J. Kinloch, C.C. Lau and J.G. Williams, The peeling of flexible laminates, International Journal of Fracture 1994; 66: 45-70.

34. W. Heukelom, P. Wijga. Bitumen testing: an introduction to the use of test methods at the Koningkijke/Shell-Laboratorium, Amsterdam; 1973.

35. L.T. Mo, M. Huurman, S.P. Wu and A.A.A. Molenaar. Bitumen-stone adhesive zone damage model for the meso-mechanical mixture design of ravelling resistant porous asphalt concrete. International Journal of Fatigue 2011; 33: 1490-1503.

36. IC Peel software. http://www3.imperical.ac.uk/meadhesion/testprotocols/peel

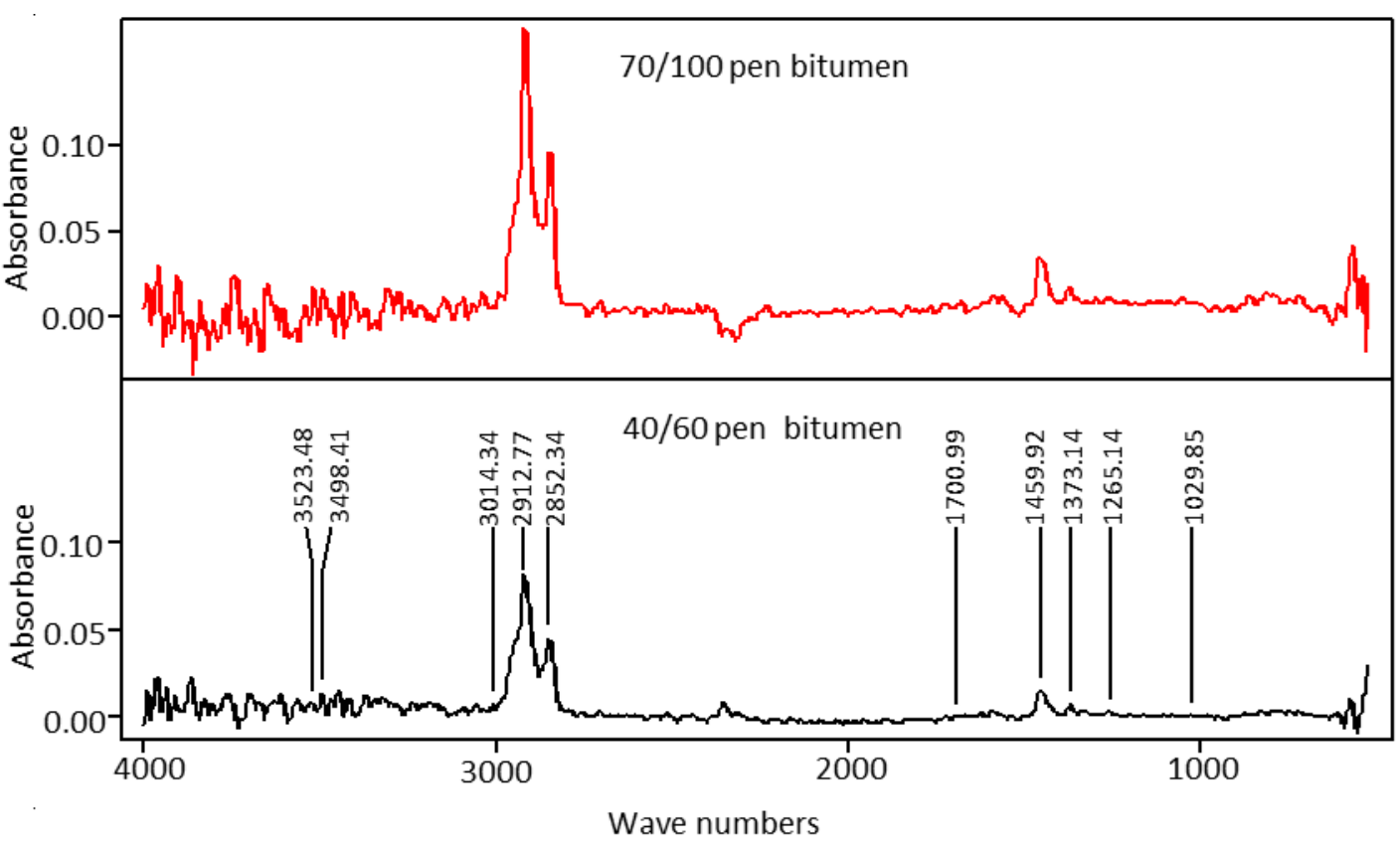

Figure 1. FTIR test result of both base bitumen 

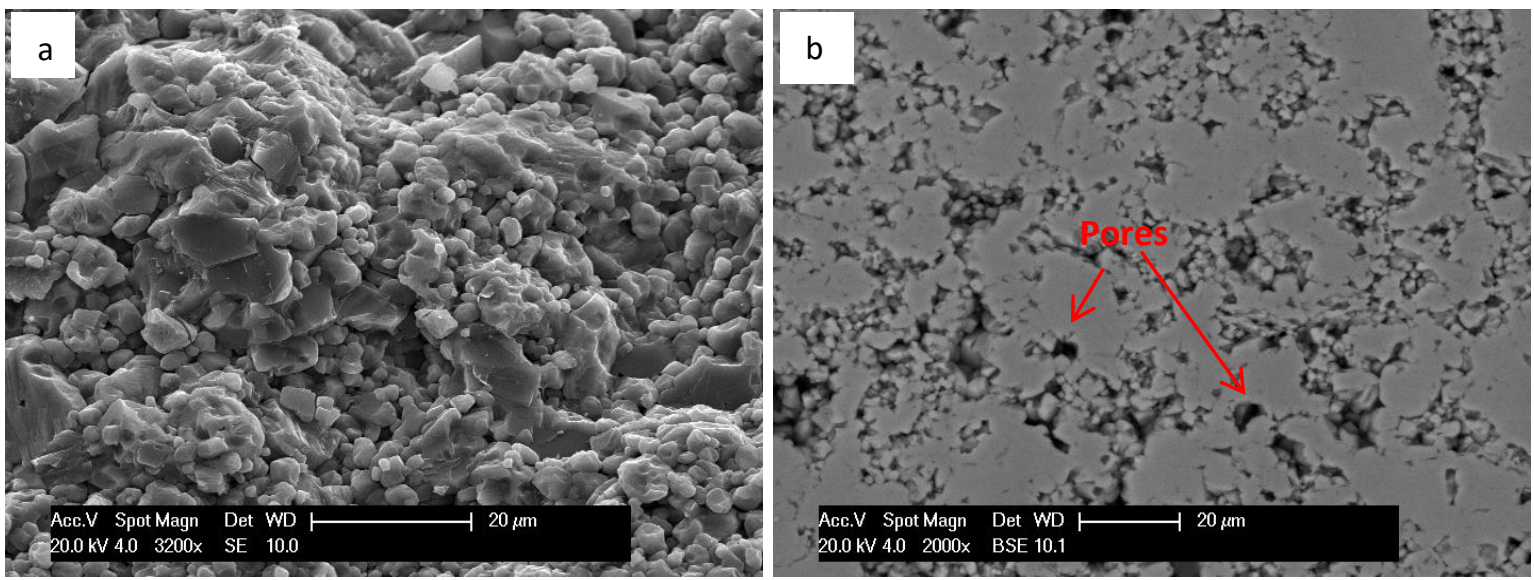

Figure 2. SEM micrographs of limestone in terms of (a) SE and (b) BSE
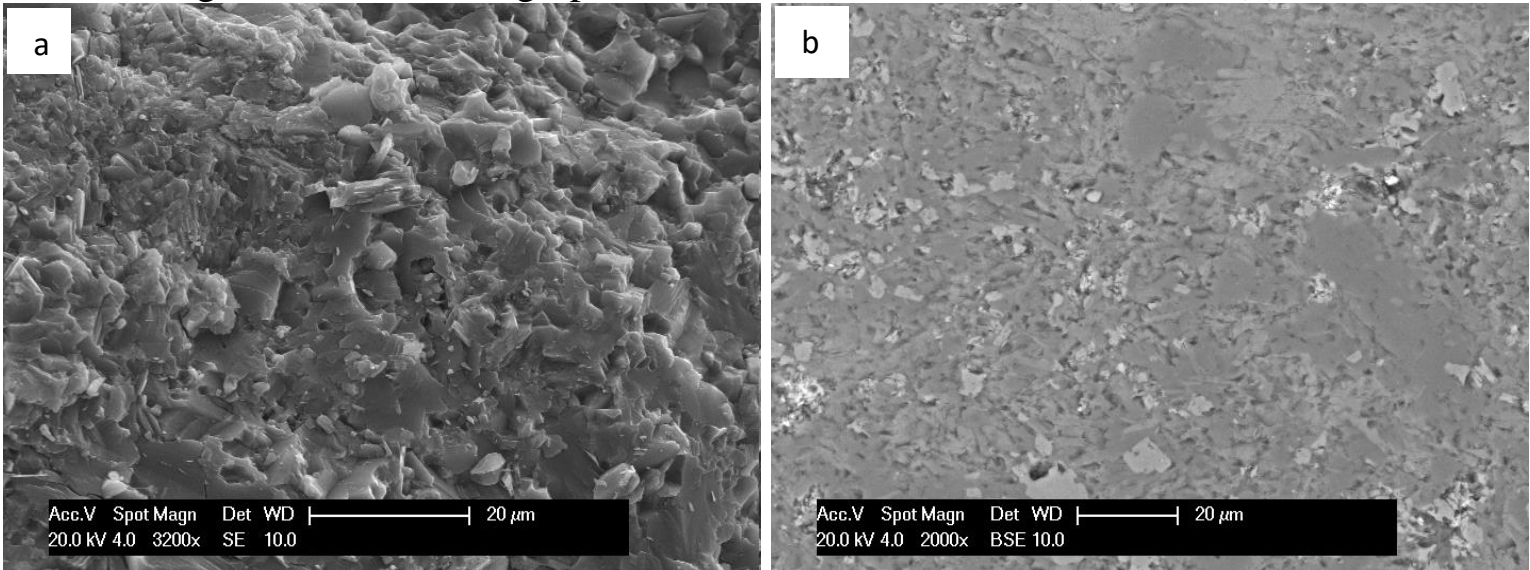

Figure 3. SEM micrographs of granite in terms of (a) SE and (b) BSE

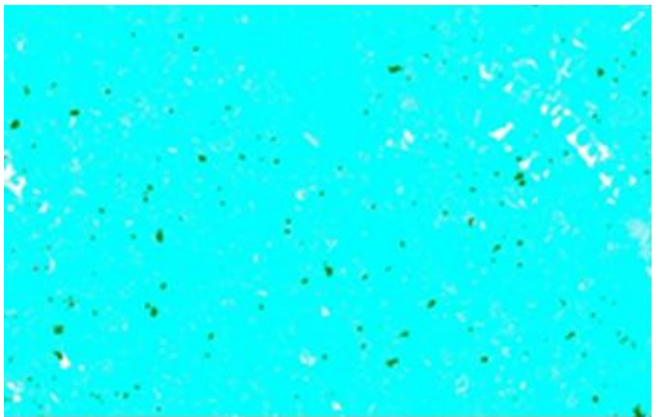

(a)

$1 \square$ calcite

$2 \square$ quartz

$3 \square$ iron_oxide

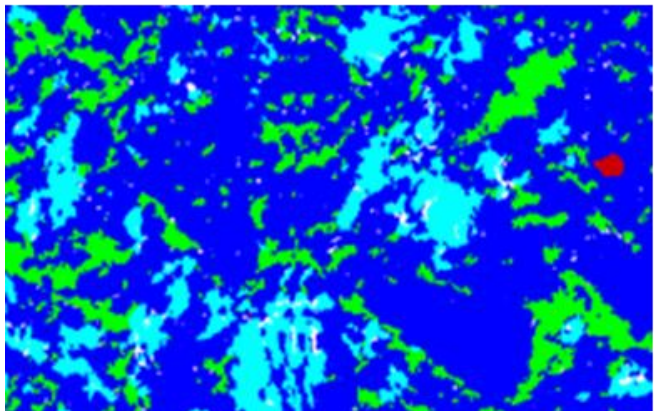

(b)

Figure 4. Mineral mosaic of (a) limestone and (b) granite 


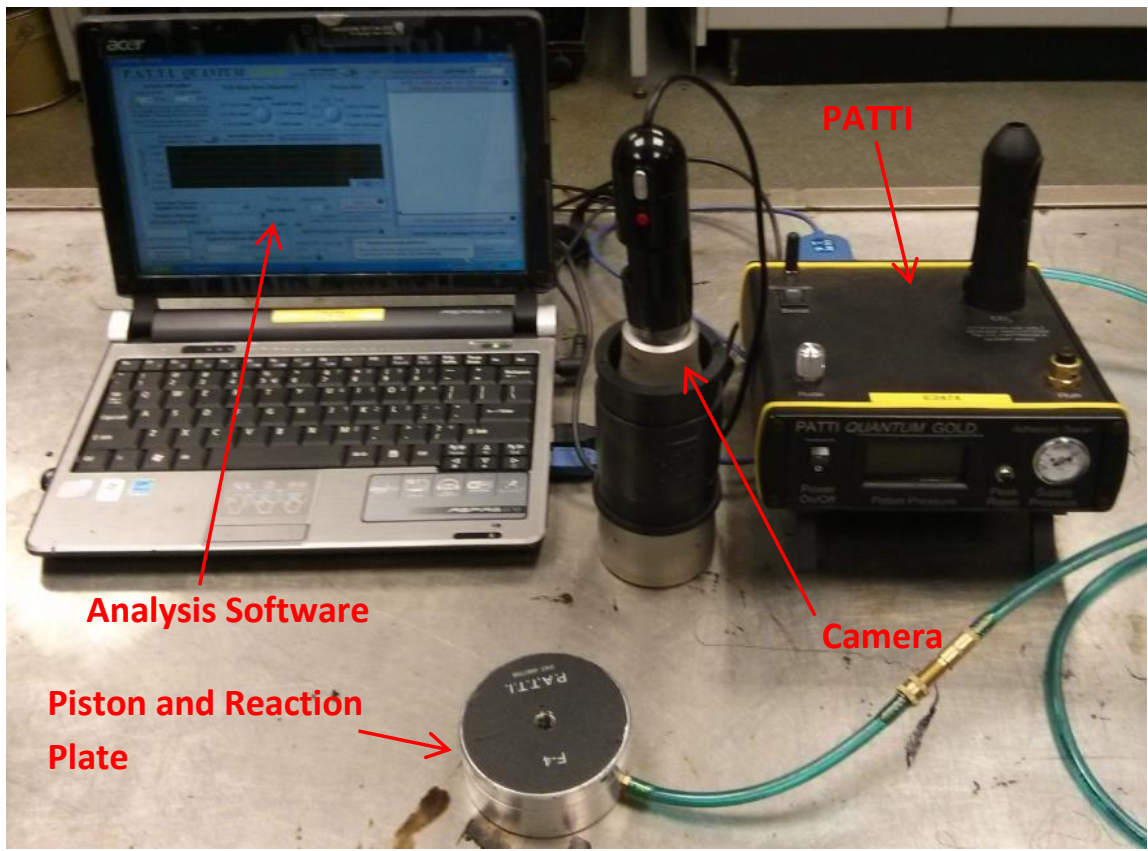

Figure 5. Equipment associated with PATTI test PULLING FORCE

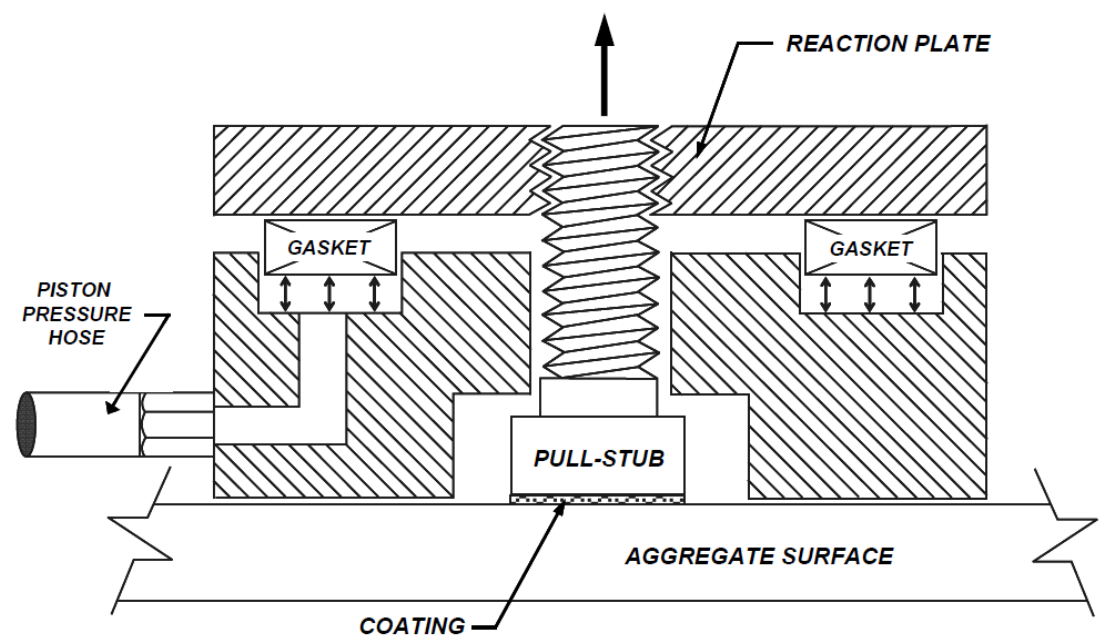

Figure 6. Cross-section view of piston attached to pull-stub [31]
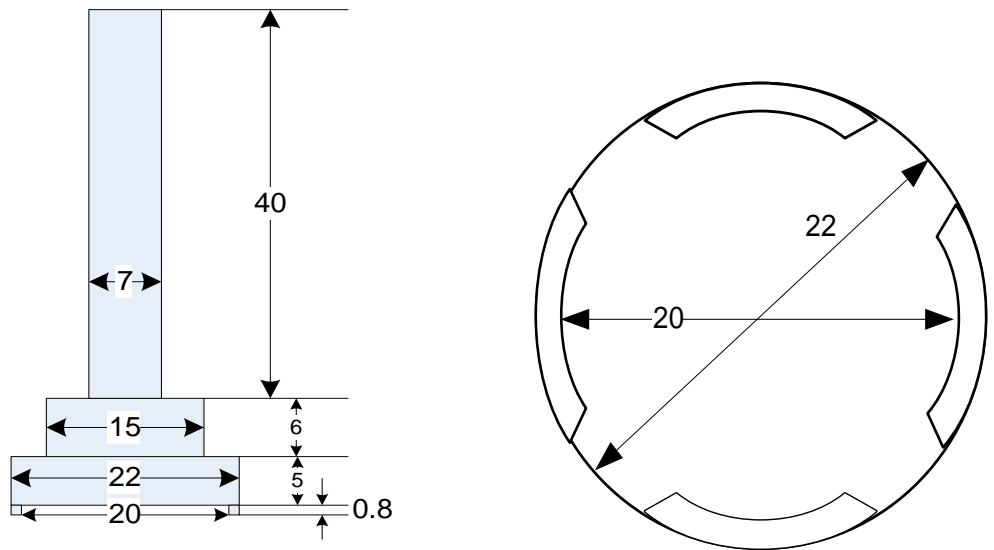

Figure 7. Pull-stub in profile and bottom views [dimensions in $\mathrm{mm}$ ] 

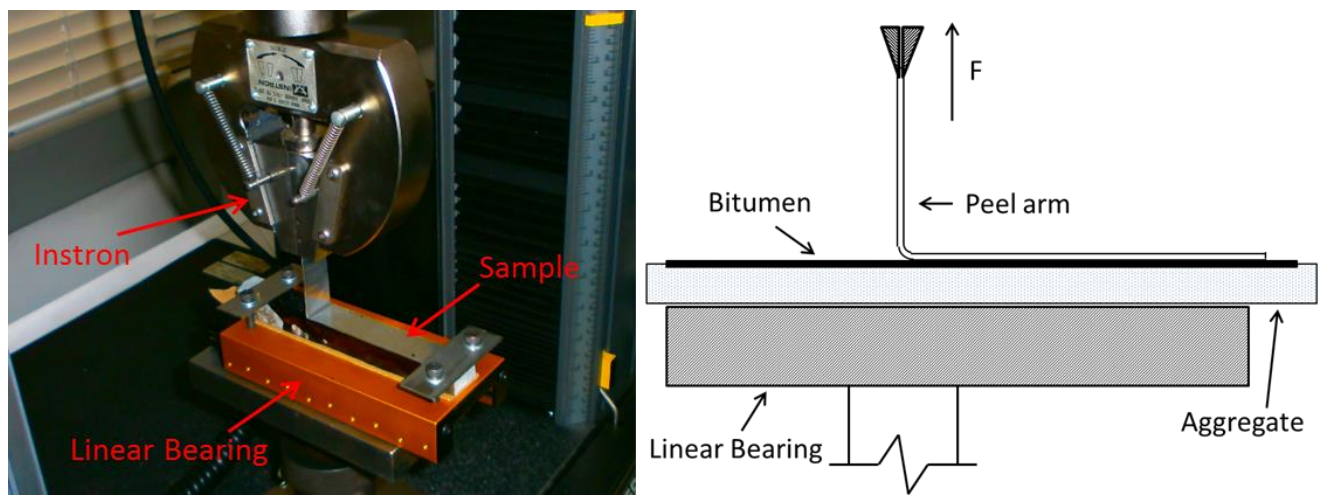

Figure 8. Details of peel test equipment

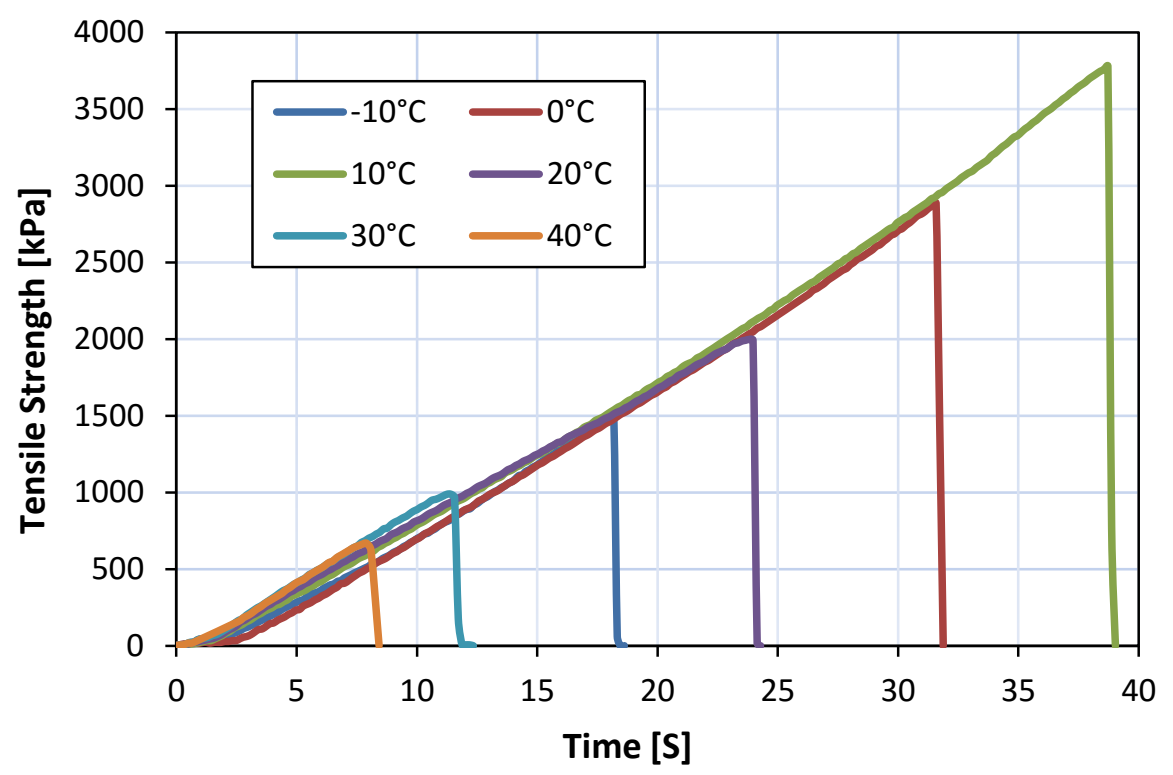

Figure 9. Tensile strength versus loading time

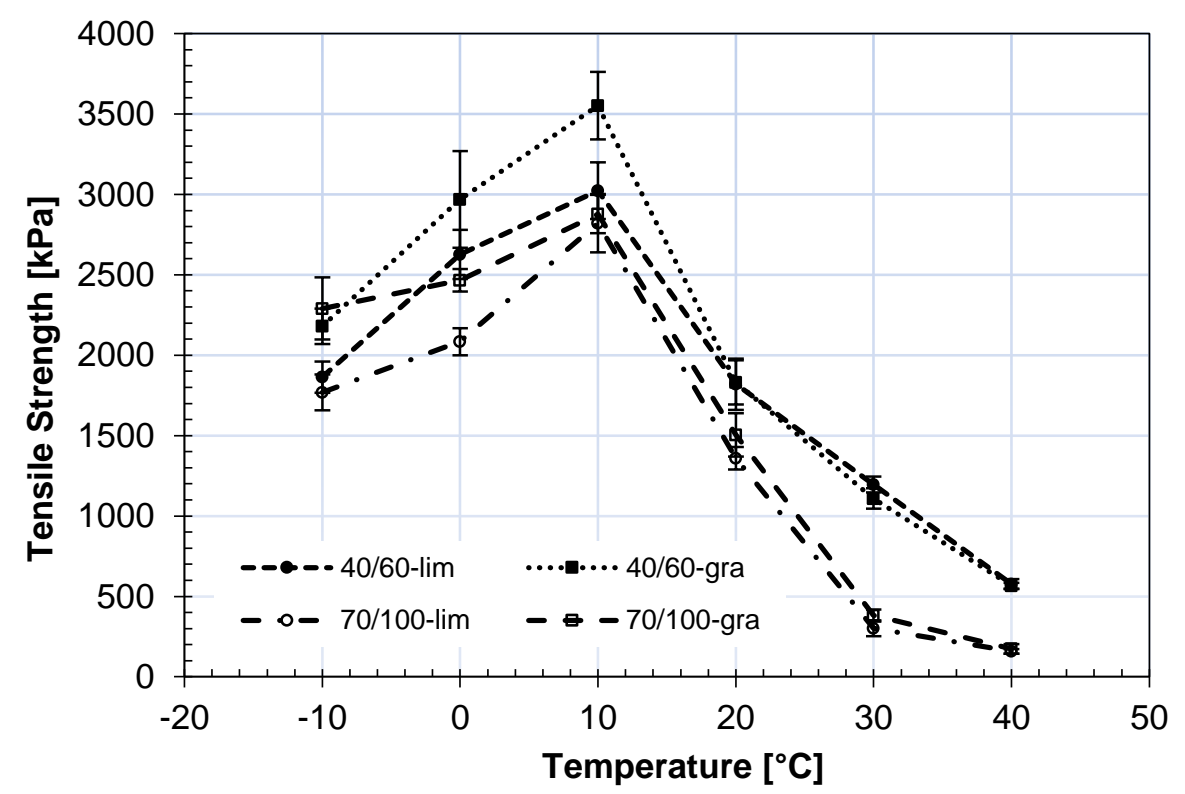

Figure 10. Tensile strengths at different temperatures 


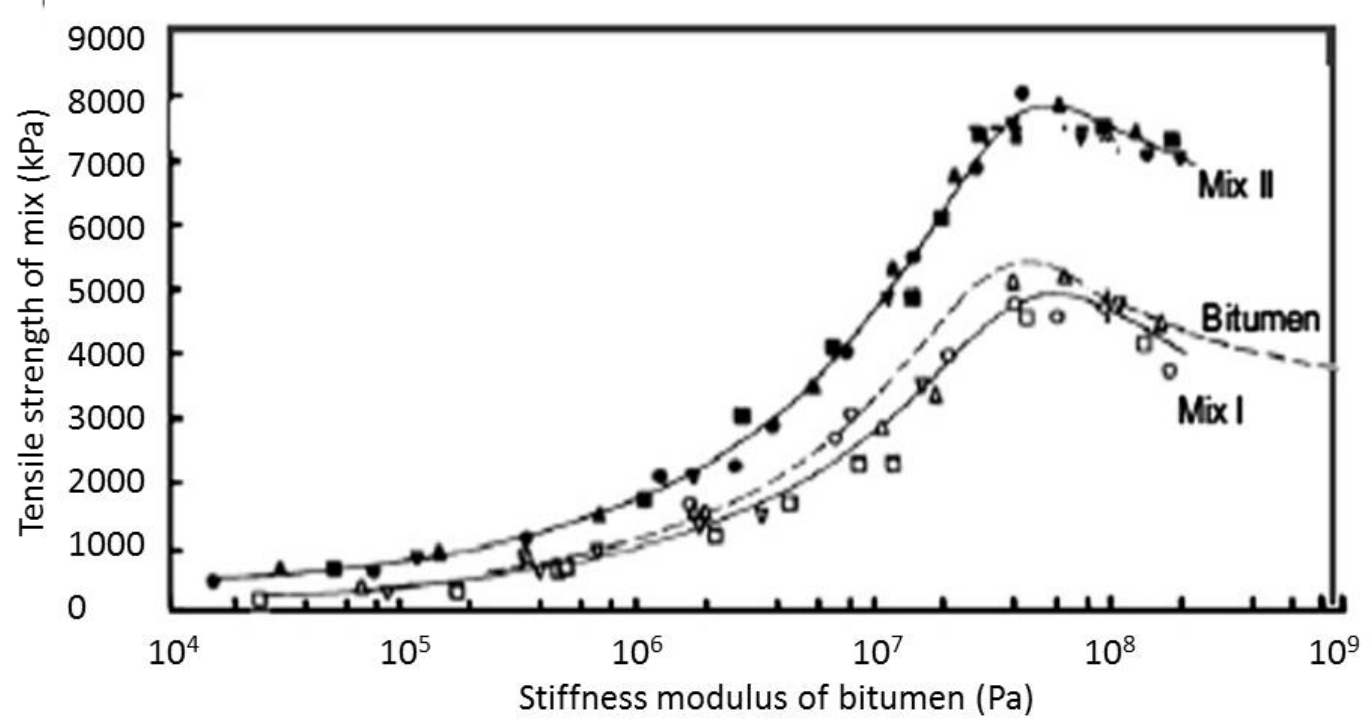

Figure 11. Bitumen stiffness modulus versus tensile strength reported by Heukelom and Wijga [34]
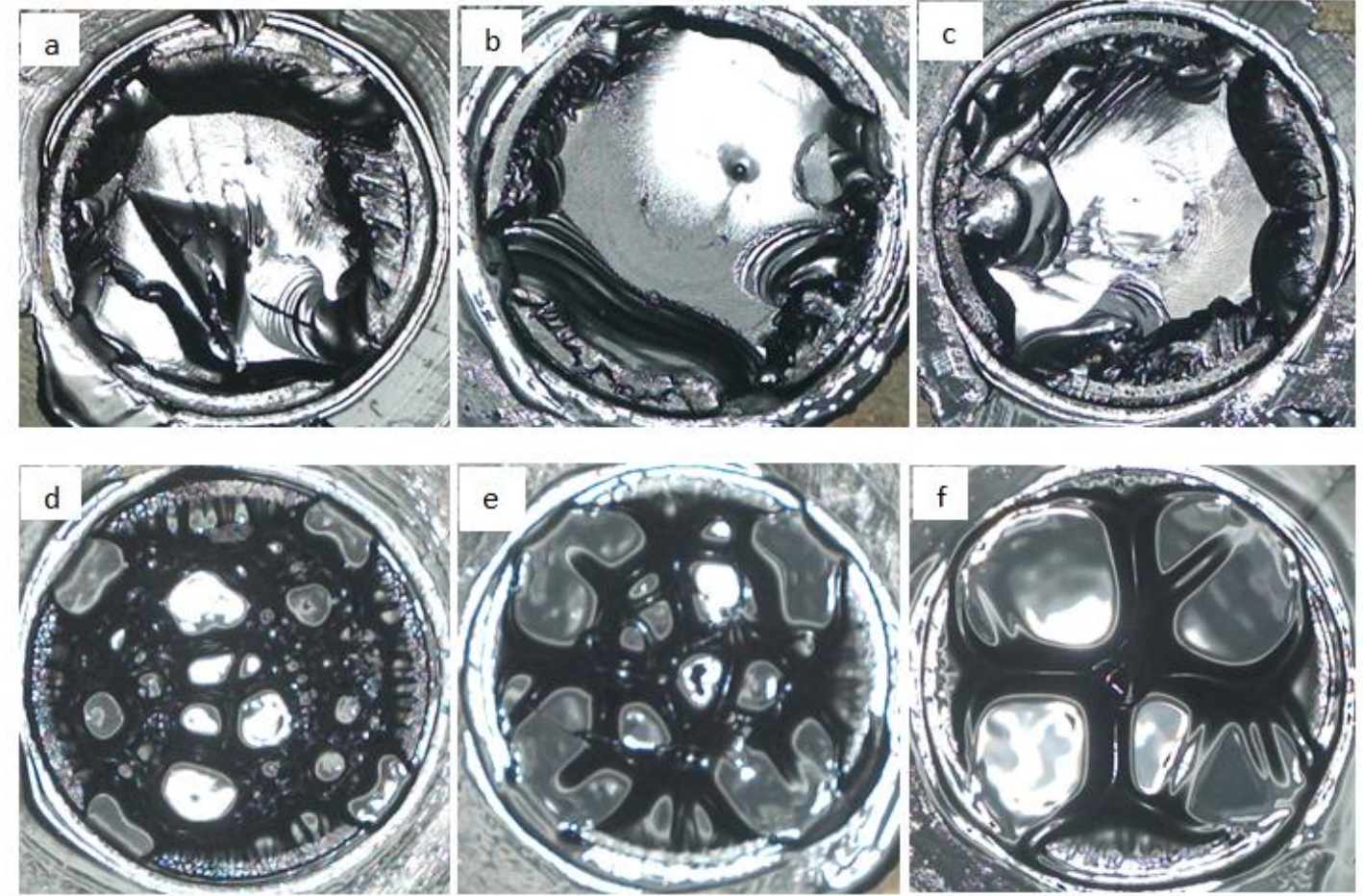

Figure 12. Failure surfaces at different temperatures: (a) $-10^{\circ} \mathrm{C}$, (b) $0^{\circ} \mathrm{C}$, (c) $10^{\circ} \mathrm{C}$, (d) $20^{\circ} \mathrm{C}$, (e) $30^{\circ} \mathrm{C}$ (f) $40^{\circ} \mathrm{C}$. 


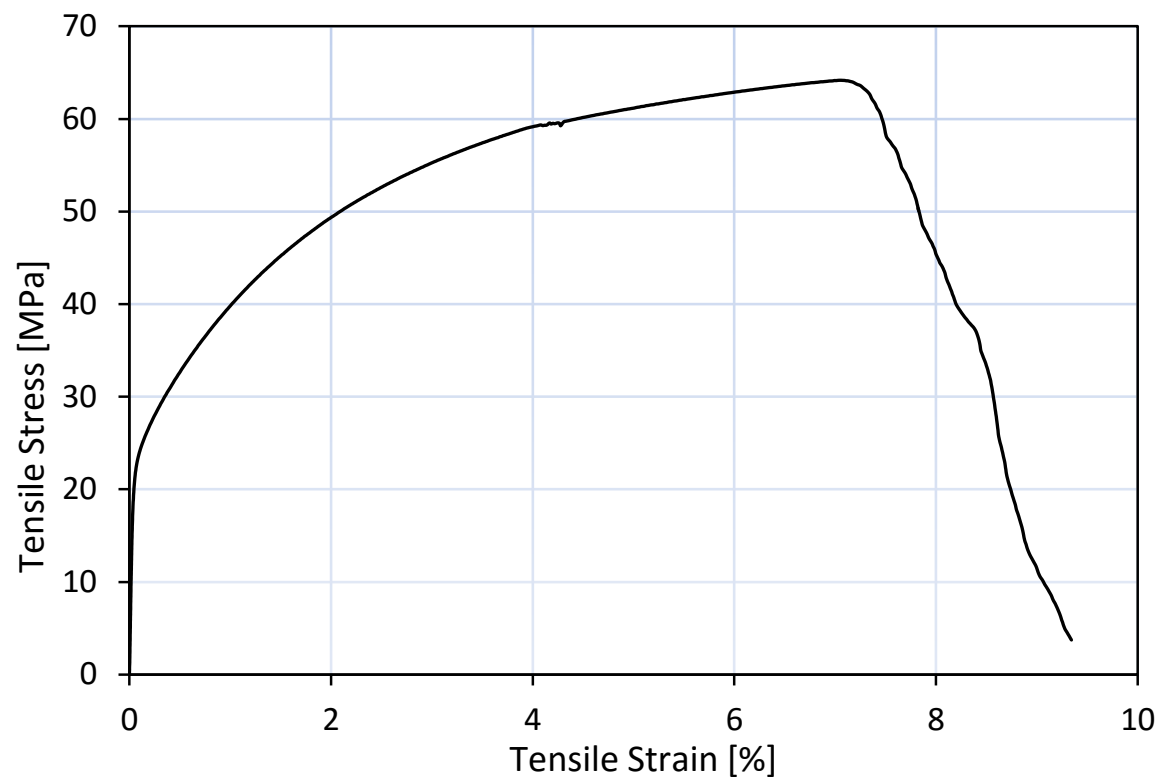

Figure 13. Stress-strain curve of peel arm test

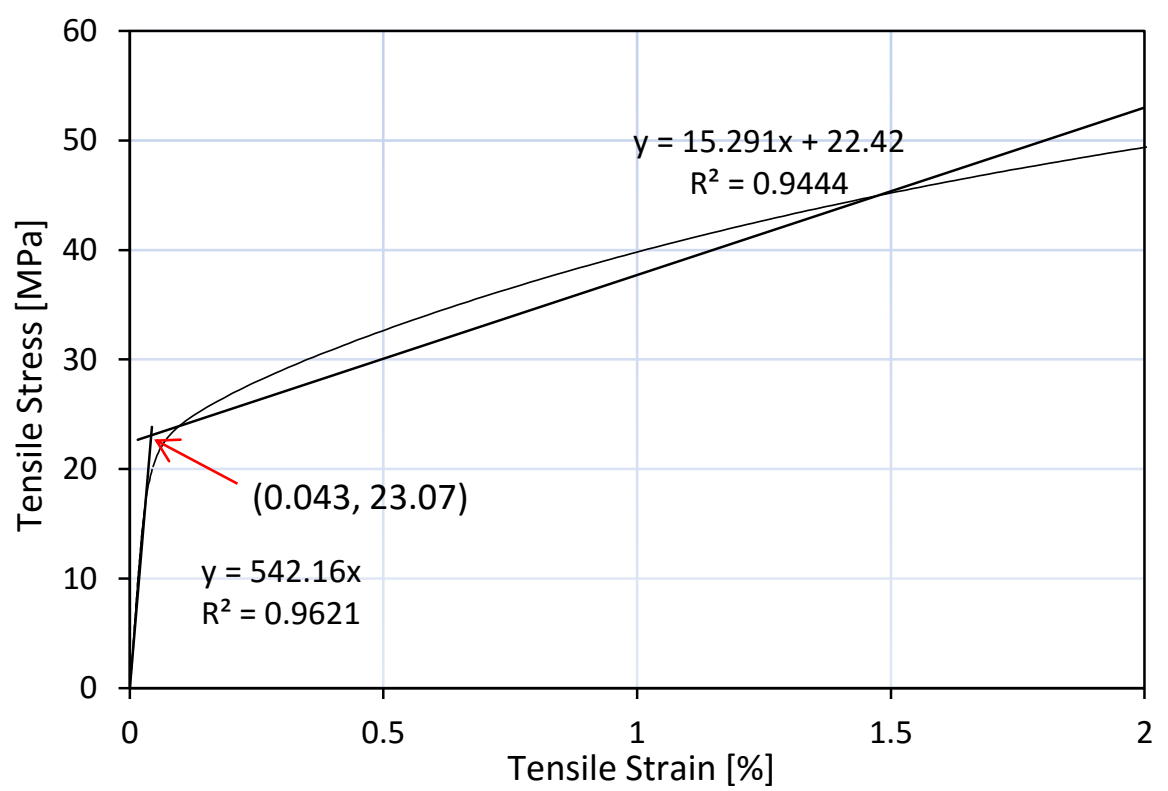

Figure 14. Tensile stress-strain curve fitted using bilinear model 


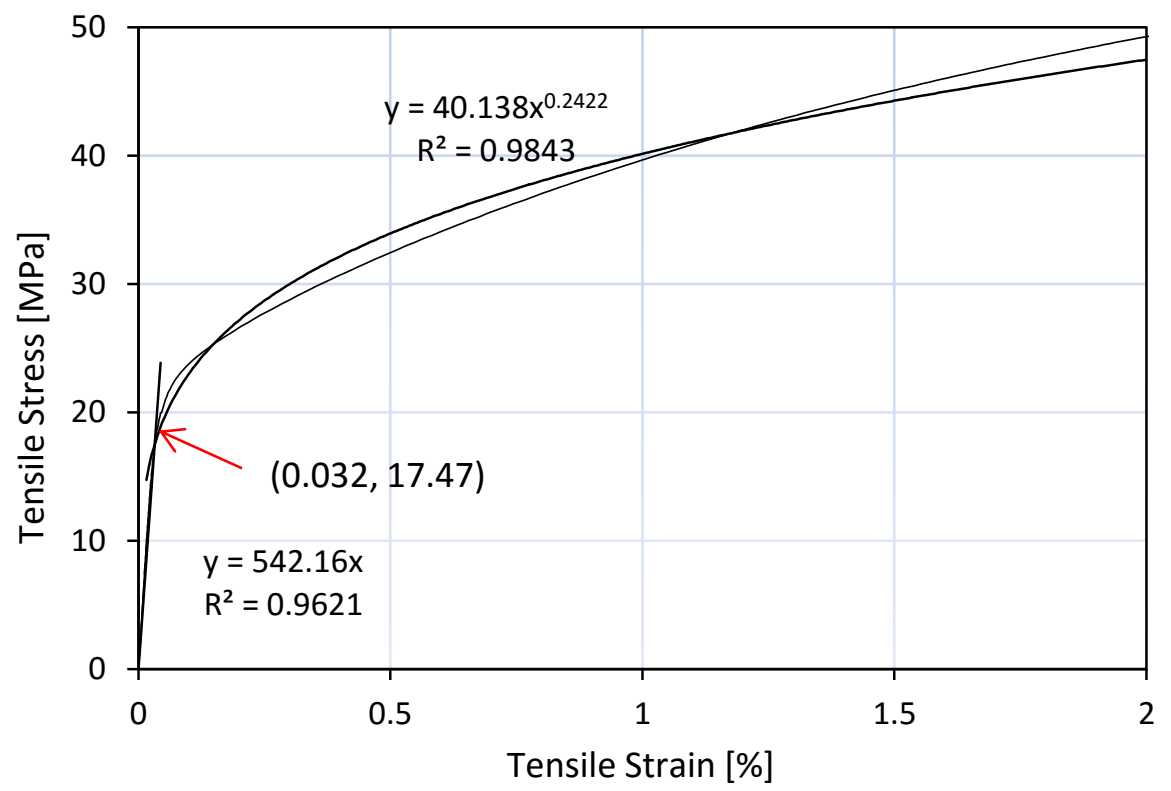

Figure 15. Tensile stress-strain curve fitted using power law model

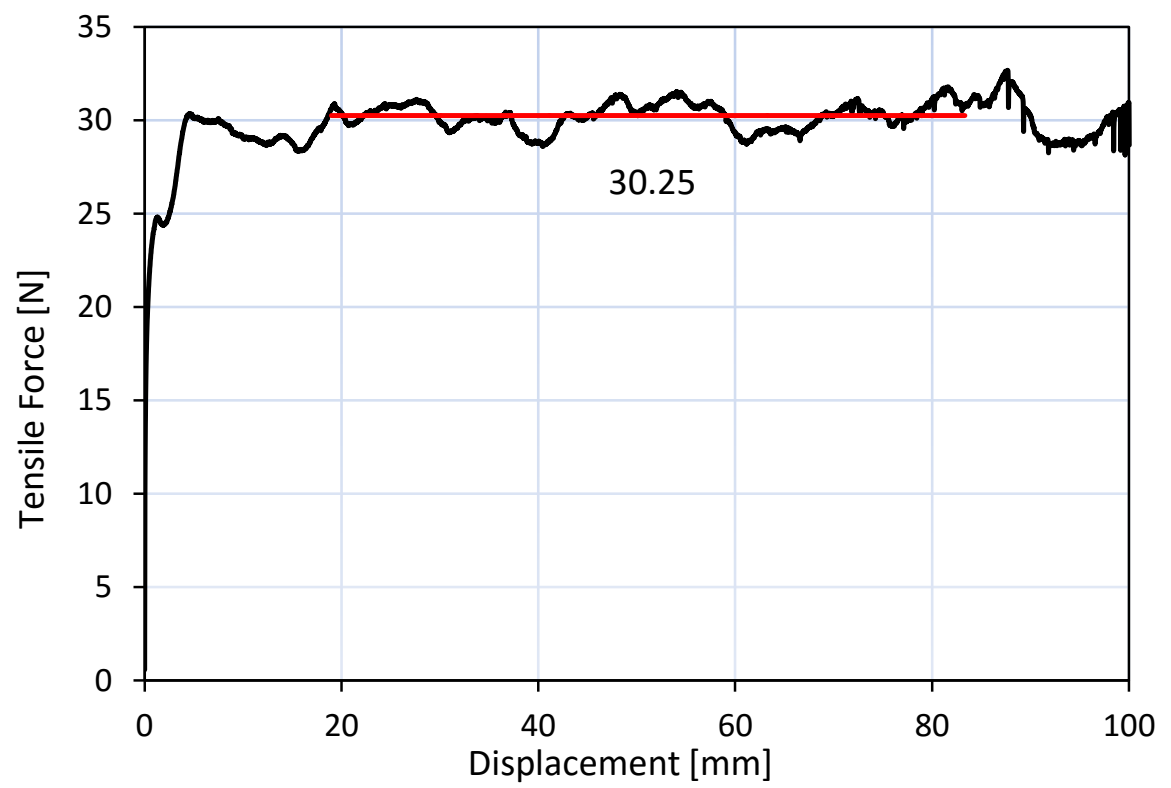

Figure 16. Measured tensile stress-strain curve for specimen prepared by 40/60 pen bitumen and limestone substrate with $0.25 \mathrm{~mm}$ film thickness 


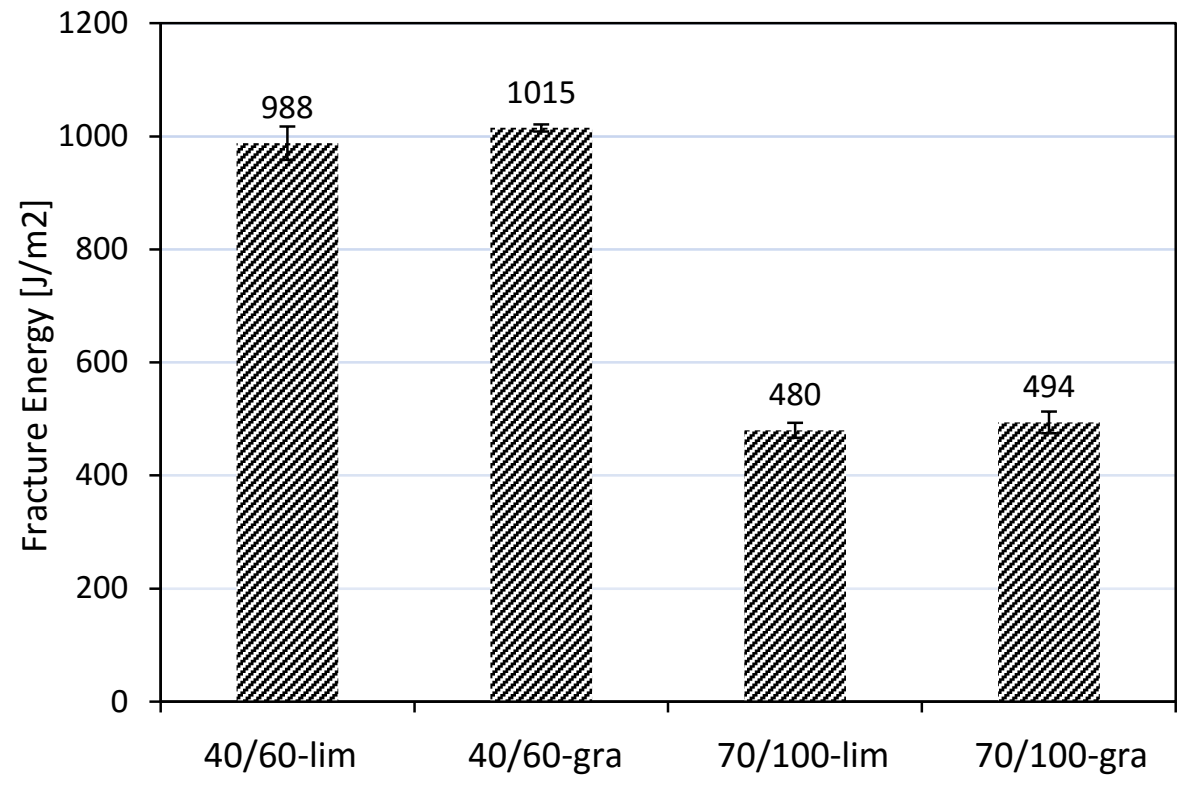

Figure 17. Fracture energy results according to bilinear model

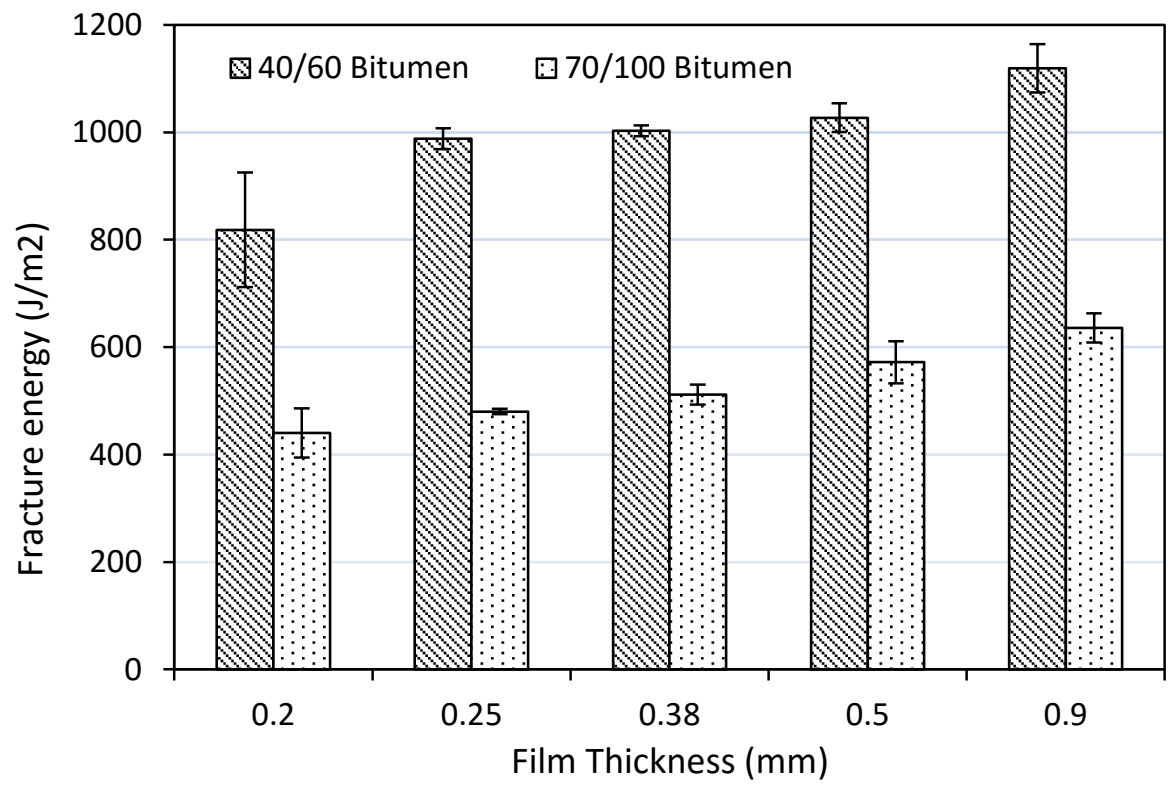

Figure 18. Fracture energy of bitumen-limestone specimen at different film thicknesses

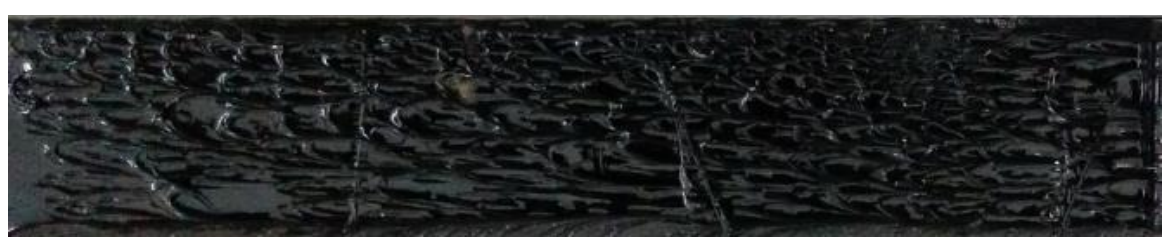

Figure 19. Failure surface of Peel Test specimen with $0.25 \mathrm{~mm}$ film thickness 


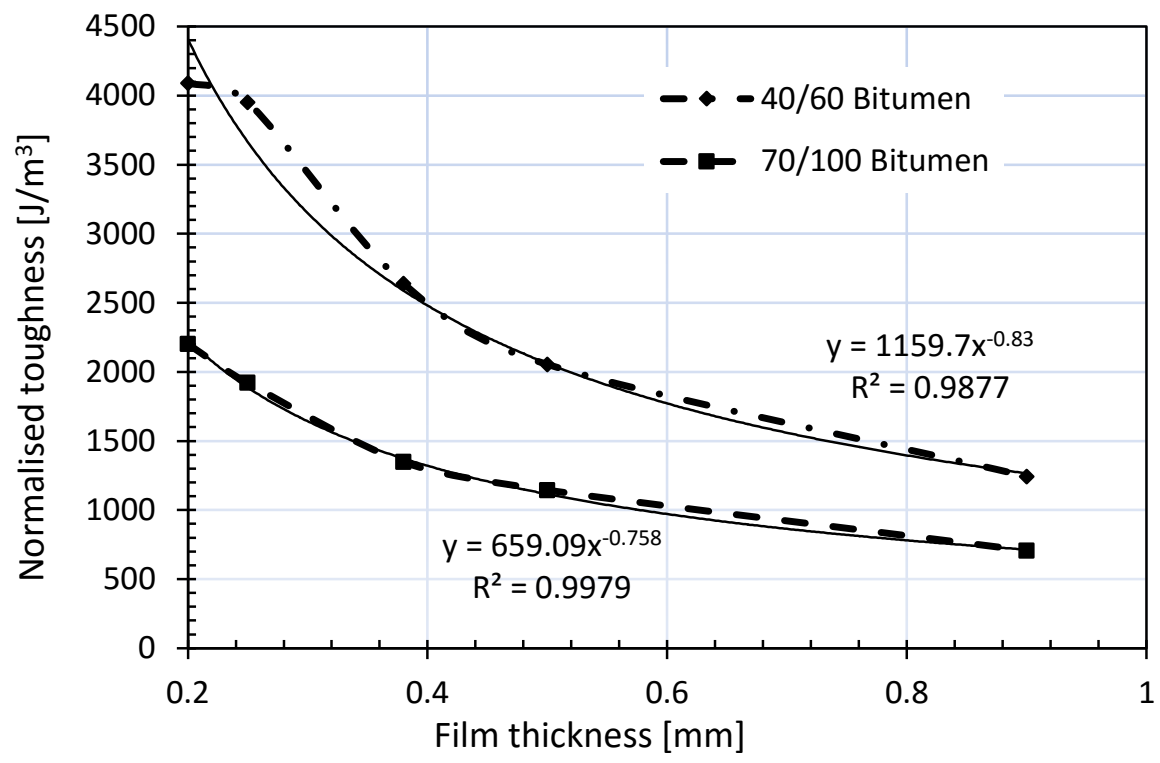

1

3

4

5

6

7

8

9

10

11

Figure 20. Relationship between normalised toughness and film thickness of bitumen

Table 1 Mineral composition of limestone identified by MLA analysis

\begin{tabular}{ll}
\hline Mineral & Wt\% \\
\hline Calcite & 99.33 \\
Quartz & 0.65 \\
Iron-oxide & 0.02 \\
Total & 100.00 \\
\hline
\end{tabular}

12

13

14

Table 2 Mineral composition of granite identified by MLA analysis

\begin{tabular}{ll}
\hline Mineral & Wt\% \\
\hline Albite & 73.17 \\
Chlorite & 15.58 \\
Anorthite & 10.75 \\
Apatite & 0.17 \\
Iron-oxide & 0.33
\end{tabular}

Total

100.00 
1 Table 3 Elemental composition of limestone and granites measured by MLA

\begin{tabular}{lll}
\hline Element & Limestone $(\%)$ & Granite $(\%)$ \\
\hline $\mathrm{C}$ & 11.92 & 0.00 \\
$\mathrm{Al}$ & 0.00 & 10.97 \\
$\mathrm{Ca}$ & 39.78 & 1.62 \\
$\mathrm{~F}$ & 0.00 & 0.01 \\
$\mathrm{Fe}$ & 0.02 & 3.04 \\
$\mathrm{H}$ & 0.00 & 0.20 \\
$\mathrm{Mg}$ & 0.00 & 1.84 \\
$\mathrm{Na}$ & 0.00 & 6.42 \\
$\mathrm{O}$ & 47.99 & 48.07 \\
$\mathrm{P}$ & 0.00 & 0.03 \\
$\mathrm{Si}$ & 0.30 & 27.80 \\
Total & 100.00 & 100.00 \\
\hline
\end{tabular}

3 Table 4. Plastic bending parameters of the peel arm

\begin{tabular}{lll}
\hline Model type & Parameters & Quantity \\
\hline \multirow{3}{*}{ Bi-linear fit } & Low strain modulus, $\mathrm{E}_{1}$ & $54.2 \mathrm{GPa}$ \\
& High strain modulus, $\mathrm{E}_{2}$ & $1.53 \mathrm{GPa}$ \\
& Yield strain, $\varepsilon_{\mathrm{y}}$ & $0.043 \%$ \\
& $\alpha\left(\mathrm{E}_{2} / \mathrm{E}_{1}\right)$ & 0.028 \\
& Yield stress, $\sigma_{\mathrm{y}}$ & $23.07 \mathrm{MPa}$ \\
\hline \multirow{3}{*}{ Power law fit } & Low strain modulus, $\mathrm{E}_{1}$ & $54.2 \mathrm{GPa}$ \\
& Constant, $\mathrm{n}$ & 0.2422 \\
& Yield strain, $\varepsilon_{\mathrm{y}}$ & $0.032 \%$ \\
\hline
\end{tabular}

5

6

7

8 